\title{
Effects of Artificial Islands Construction on the Spatial Distribution and Risk Assessment of Heavy Metals in the Surface Sediments from a Semi-closed Bay (Longkou Bay), China
}

\author{
Peng Ren ${ }^{1} \cdot \mathrm{He} \mathrm{Zhu}^{2}$ (D) Zhigao Sun $^{3} \cdot$ Chuanyuan Wang ${ }^{4}$
}

Received: 28 July 2020 / Accepted: 21 October 2020

(c) Springer Science+Business Media, LLC, part of Springer Nature 2020

\begin{abstract}
Artificial islands construction can significantly influence the spatial distribution of heavy metals in inshore sediments. In this study, the distribution and contamination of heavy metals $(\mathrm{Cd}, \mathrm{Co}, \mathrm{Cr}, \mathrm{Cu}, \mathrm{Ni}, \mathrm{Pb}, \mathrm{Zn}, \mathrm{As}$ and $\mathrm{Hg}$ ) in inshore sediments of the Longkou Bay and artificial island adjacent areas were investigated in 2013 and 2014, respectively. Results showed that the contents of heavy metals increased in the Longkou Bay and decreased in the west of the artificial island in 2014 compared with 2013. The contamination and potential eco-risk of heavy metals in the sediments were higher in 2014 than those in 2013. Cd and $\mathrm{Hg}$ showed a high potential eco-risk in LK02, and other metals were in the lower level. The results indicated that after the construction of artificial islands in the Longkou Bay, the contamination and eco-risk of heavy metals in the sediments markedly increased in the Longkou Bay.
\end{abstract}

Keywords Heavy metals · Contamination assessment · Eco-risk · Artificial islands · Longkou Bay

Heavy metals are considered to the primary pollutants in the coastal environments due to their high toxicity, persistence and non-degradability (Armid et al. 2014; Zhang et al. 2016; Tian et al. 2018). Because of their unique natural conditions

Electronic supplementary material The online version of this article (https://doi.org/10.1007/s00128-020-03032-3) contains supplementary material, which is available to authorized users.

He Zhu

zhuhe@imde.ac.cn

$\triangle$ Zhigao Sun

zhigaosun@163.com

1 Qingdao National Laboratory for Marine Science and Technology, Qingdao 266061, China

2 Key Laboratory of Mountain Surface Processes and Ecological Regulation, Institute of Mountain Hazards and Environment, Chinese Academy of Sciences, Chengdu 610041, China

3 Key Laboratory of Humid Subtropical Eco-geographical Process (Fujian Normal University), Ministry of Education, Fuzhou 350007, China

4 Key Laboratory of Coastal Zone Environment Processes and Ecological Remediation, Yantai Institute of Coastal Zone Research, Chinese Academy of Sciences, Yantai 264003, People's Republic of China and geographical location, the coastal zones and bays are the areas where human activities are most frequently disturbed (Wang et al. 2014; Yan et al. 2016). Consequently, huge amounts of metals were discharged into the estuary and coastal environment through runoff and atmospheric transport (Xu et al. 2016; Han et al. 2017). According to the Bulletin of Marine Environmental Quality of China, about 17.6 million tons of pollutants were discharged into the sea in China in 2014. On account of the strong metal-binding capacity, easily removed and released to the overlying aqueous, sediments serve as repositories and source of heavy metals (Usman et al. 2013). However, once the conditions of sedimentary environment changed, heavy metals fixed in sediments can be dissolved into the water again, causing secondary contaminations (Hill et al. 2013; Duan et al. 2018; Zhu et al. 2019). Therefore, heavy metals in the sediments can be good indicators of regional contamination condition which contain valuable geological and environmental information.

As the leader city of the overall concept of the development of blue economic zones in Shandong Peninsula, Longkou city's development is obviously limited by the narrow land area and insufficient space resources. In order to solve this problem and maintain sustained economic growth steadiness, Longkou City adopted the combination 
of artificial islands and block groups reclamation to construct the offshore artificial islands group. The construction of offshore artificial islands is bound to change the natural coastline of Longkou Bay, causing changes in hydrodynamic conditions in Longkou Bay. Thus, that will lead to changes in tidal fields and characteristics of erosion and deposition in and around the bay. Meanwhile, the variation of the shoreline caused by land reclamation and coastal engineering was the main factor affecting the accumulation of heavy metal contents of sediment profiles (Pan et al. 2000; Tam and Wong 2000). Several studies have been investigated the content, distribution and sources of heavy metals in the sediments in Laizhou Bay (Zhuang and Gao, 2014; Zhang et al. 2017) and Bohai Bay (Xu et al. 2016; Ding et al. 2018), and they mainly considered the nature sources and industrial sources were important factors affecting the heavy metals, but did not take the construction of the large scale offshore artificial island into consideration.

Longkou Bay, locates in the northeast of Laizhou Bay, northeast of China, is a logarithmic spiral semi-open bay, with shallow sea plain landform in the bay, and the hydrodynamic force is relatively weak with no significant discharge of sediments and dynamic balance existed at the top of Longkou Bay. After decades of booming industrialization and rapid population growth around Longkou Bay, a large amount of contaminants has been discharged into the bay, which has a detrimental impact on both the ecological environment and human health. In view of this, based on the heavy metal content in the surface sediment collected from Longkou Bay and the adjacent sea areas in 2013 and 2014, we combined with the TOC content, and particle size of the sediments, using a variety of evaluation methods to evaluate the status of heavy metal contamination and ecological risk of this area, in order to know the current contamination status and whether it was affected by the construction of the large scale offshore artificial island and provide basic data support for protecting the coastal ecological environment.

\section{Materials and Methods}

Ten surface sediments $(0-5 \mathrm{~cm})$ were selected to collect from inshore and adjacent sea areas of the Longkou Bay by using a stainless steel grab sampler in September 2013 and 2014, respectively (Fig. 1). After sampling, sediments were carefully stored in acid-rinsed polyethylene bags and stored at $-20^{\circ} \mathrm{C}$ in the dark until further analysis. General information of the surface sediments in sampling stations of the Longkou Bay was given in Table S1.

Grain size of the surface sediments were measured according to Fang et al. (2015), and measured by using a Mastersizer 2000 Laser Particle Size Analyzer (Malvern Panalytical, UK). Three glasses of grain sizes were divided: clay $(<4 \mu \mathrm{m})$, silt $(4-63 \mu \mathrm{m})$, and sand $(>63 \mu \mathrm{m})$ (Folk and Ward 1957). The total organic carbon (TOC) in the sediment was obtained by subtracting the inorganic carbon from the total carbon, and measured in duplicates by using an Elemental Analyzer (Thermo Fisher Flash 2000), with a standard deviation of $\pm 0.02 \%(n=6)$ for TOC. The concentrations of heavy metals in the sediments were measured according to Zhao et al. (2016). Sample solution and reagent blanks were analyzed for $\mathrm{Pb}, \mathrm{Cu}, \mathrm{Zn}, \mathrm{Ni}, \mathrm{Cd}, \mathrm{Cr}$, and $\mathrm{As}$ by using an Inductively Coupled Plasma-Mass Spectroscopy (ICPMS) (Agilent Company, America). And the concentration of $\mathrm{Hg}$ was measured using Atomic Fluorescence Spectrometry (AFS-930) (Jitian Company, Beijing).

In order to monitored the quality of chemical analysis and examine the accuracy of the data, standard reference

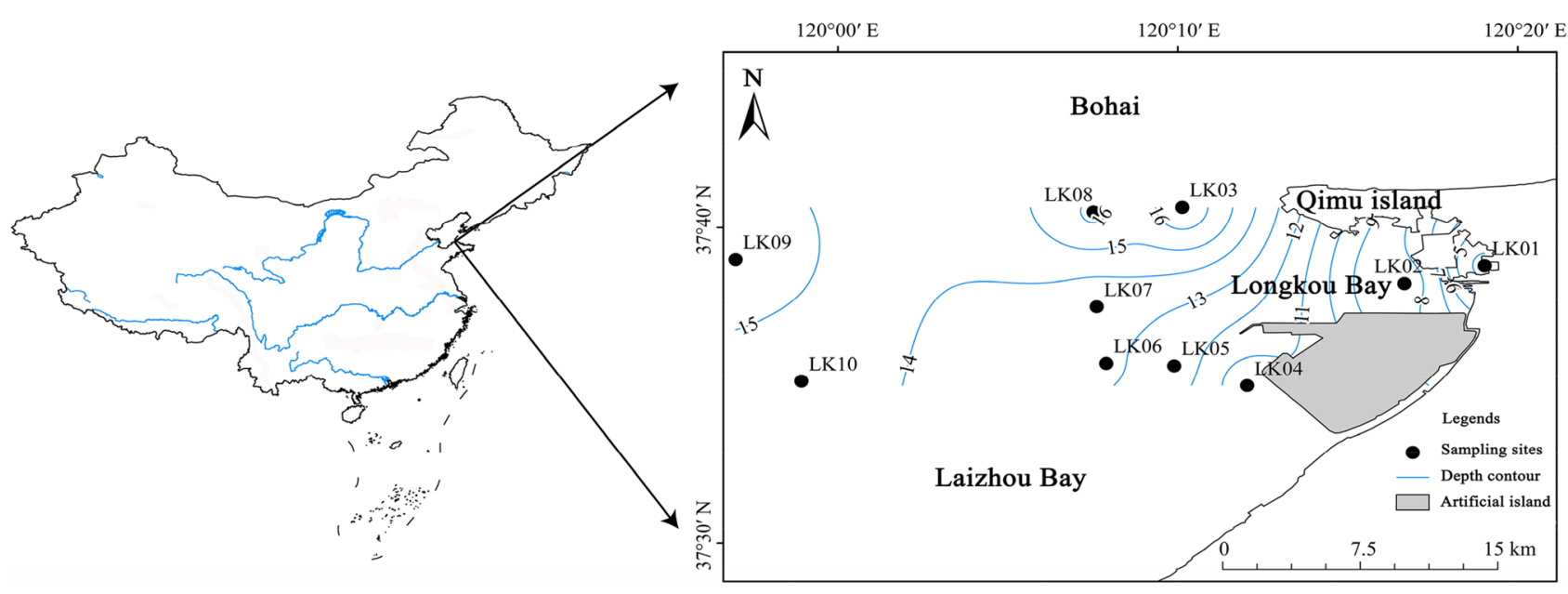

Fig. 1 Map showing the sampling sites of the surface sediments collected in the Longkou Bay and the adjacent sea areas 
materials (GBW07401) from the National Research Center for Standards of China were analyzed during the process. And all sediment samples were analyzed in duplicates. According to the measurement of the repeated samples and reference materials, the relative standard deviation was below 5\% for ICP-MS and below 1\% for AFS. And the recovery of the reference materials was $96 \%-105 \%$.

The geo-accumulation index (Igeo) is a common criterion to assess the contamination of heavy metals in the sediments, which was originally proposed by Muller (1969). It can be calculated by the Eq. (1) shown in the supplementary materials, and seven classes of geo-accumulation index had distinguished as shown in Table S2. The potential ecological risks not only reflect the contamination level of heavy metals, but also combines the toxicity and the response of the environment (Hakanson 1980). It can be calculated by the Eq. (2) and (3) shown in the supplementary materials, and the classifications of $E_{r}^{i}$ and $E_{R I}$ are listed in Table S3.

Pearson correlation analysis was applied to establish the relationships between heavy metals and sediment physiochemical properties by the software package SPSS 16.0 for Windows. The study area and depths of Laizhou Bay were performed by the software ArcGIS 10.2 with the method of inverse distance weighted (IDW).

\section{Results and Discussion}

The TOC (\%) and grain size composition were measured in order to get the general characteristics information of the surface sediments. The sediments were predominantly composed of silt (55.6\%-71.4\%, mean: 63.2\%), followed by sand (8.8\%-35.6\%, mean: $18.7 \%)$ and clay $(8.4 \%-27.1 \%$, mean: $18.0 \%)$. The contents of TOC varied between $0.18 \%$ and $0.76 \%$ with mean contents of $0.50 \%$ in the surface sediments by dry weight. The highest and lowest contents of TOC were observed at LK02 and LK10 station, respectively.

The varied contents of heavy metals in surface sediments in 2013 and 2014 were showed in Table S4, respectively. The mean contents of heavy metals in sediments decreased in the order of $\mathrm{Cr}>\mathrm{Zn}>\mathrm{Cu}>\mathrm{Ni}>\mathrm{Pb}>\mathrm{Co}>\mathrm{As}>\mathrm{Cd}>\mathrm{Hg}$ both in two years. Compared with 2013, the mean contents of $\mathrm{Cd}, \mathrm{Ni}, \mathrm{Pb}, \mathrm{As}$ and $\mathrm{Hg}$ increased in 2014, while the other trace metals decreased. The largest increasing and decreasing contents of heavy metals were $\mathrm{Pb}$ and $\mathrm{Cr}$, respectively (Fig. 2).

The spatial distribution of the various trace metals in the sediments of the study area in 2013 varied widely, but were moderately variable compared with 2014 $(10 \%<\mathrm{CV}<100 \%)$. Among them, the variation coefficients of $\mathrm{Cu}$, As and $\mathrm{Hg}$ in the sediments in 2013 were relatively higher, which were $52.7 \%, 47.3 \%$ and $43.8 \%$, respectively. However, the variation coefficients of $\mathrm{As}, \mathrm{Cd}$ and $\mathrm{Hg}$ in sediments in 2014 were higher, which were $38.2 \%$, 41.6\% and $40.4 \%$, respectively (Table S4). The annual differences in the levels of various trace metals in the sediments in 2013 and 2014 shows that $\mathrm{Pb}, \mathrm{Cd}, \mathrm{As}, \mathrm{Zn}$ and $\mathrm{Cr}$ differed significantly between the 2 years $(p<0.05)$, while the content of $\mathrm{Cu}, \mathrm{Co}, \mathrm{Ni}$ and $\mathrm{Hg}$ was not significantly different between the 2 years $(p>0.05)$. On the whole, compared with the distribution of heavy metals in the study area in 2013, the content of heavy metals increased slightly in the inner bay of Longkou Bay and the western area of Qimu Island in 2014, and decreased slightly in the western area of artificial island near Laizhou Bay.

Hydrodynamic conditions are a main factor influences the distribution of heavy metals in the sediments (Wang et al. 2013; Yan et al. 2016). The artificial island generated strongly blocking effect on the water flow and the transport of sediment in the Longkou Bay, which makes the current velocity and effective wave height of the Longkou Bay sea area smaller, and has led to an increase of siltation in the northern part and inner of Longkou Bay (Zhou et al. 2014; Liu et al. 2017). The smectite content in Longkou Bay was significantly higher than that outside the bay, which also indicated that the fine sediment in Longkou Bay deposited (An et al. 2010; Ren et al. 2016). Due to the deposition of silt in the bay, heavy metals from land-based pollutants and the shipping pollutants in Longkou Port are adsorbed by fine particles and then enriched in the bay. Therefore, the heavy metal contents increased at the LK02 station. Meanwhile, there was a weak tidal current area in the southeast of Laizhou Bay, and the tidal current direction was basically parallel to the shore wall of the artificial islands, which was closed to the artificial island construction area of Longkou Bay (Bian et al. 2006). Coarse particles deposited on the artificial island shore, while fine particles are usually transported far from shore under hydrodynamic force. As mentioned above, the change of particle size must change the distribution of sediment, and the main reason for this change was the construction of artificial island. Since the sediments from the north side of Qimu island cannot enter the south side, which accompanying a slight erosion in the west the island (Feng et al. 2009). These have resulted in the deposition of some heavy metals in the LK03 station and the nearby areas in the western part of Qimu island. In addition to affect the content and distribution of heavy metals through changing the tidal current, the construction of artificial islands has impact on the sources of heavy metals.

Organic matters, Fe/Mn oxides/hydroxides and grain size composition were considered as the controlling factors in the spatial distribution of heavy metals in the sediments (Zhu et al. 2018). And correlations of heavy metals can reflect the origin and migration of these metals. Pearson correlation analysis showed that the TOC content of the sediments in the study area was highly significantly correlated with the clay 


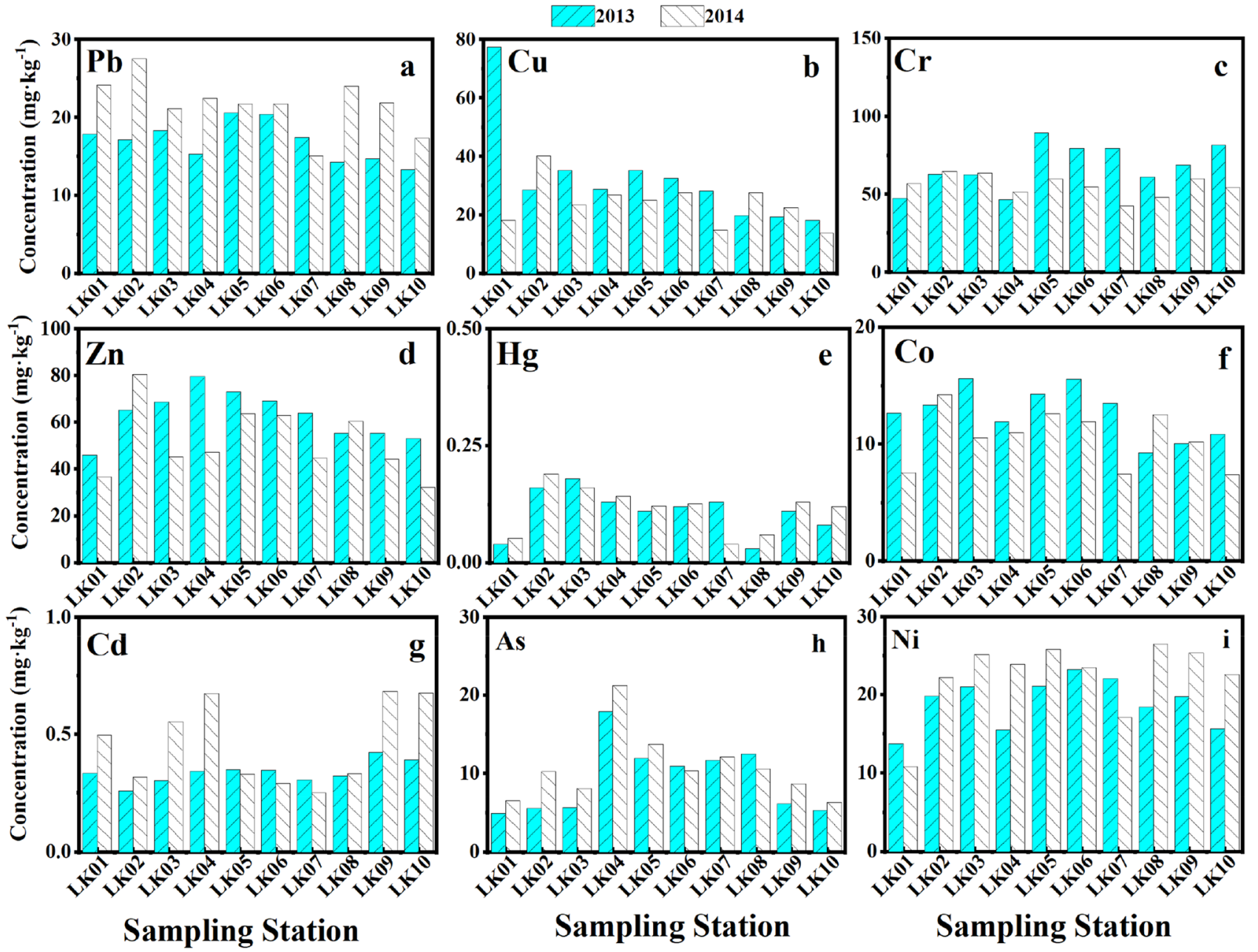

Fig. 2 Comparison of heavy metal concentrations in surface sediments at different stations in the study area between 2013 and 2014

$(p<0.01)$, was significantly positively correlated with silt $(p<0.05)$ and highly significantly negatively correlated with sand $(p<0.01)$ (Table 1), indicating that TOC is more likely to be deposited in fine particles, which is consistent with the results of Zheng et al. (2015). In addition to the negative correlations with $\mathrm{Cd}, \mathrm{Cu}$, and $\mathrm{Cr}$, TOC showed positive correlations with other trace metals, suggesting that these metals may be homologous or were related to the organic matter in the sediment. In addition to $\mathrm{Cd}$ and $\mathrm{Cr}$, other trace metals were also mostly positively correlated with fine particles. And in the study of Zhu et al. (2018), the heavy metals in the sediments correlated significantly with $\mathrm{Fe}$ and $\mathrm{Mn}$ $(p<0.01)$, and they indicated that the Fe/Mn oxides/hydroxides played important role in the distribution of heavy metals in surface sediments of the Caofeidian adjacent sea after the land reclamation, especially in the western Caofeidian.

The mean values of Geo-accumulation index (Igeo) of heavy metals were shown in Fig. 3. Our results indicated that the study area was unpolluted by these metals in 2013 . $\mathrm{Cu}$ only showed moderate degree of contamination at LK01
$($ Igeo $=1.06)$ station, whereas unpolluted at other stations. And the calculated Igeo of Cd ranged from 0 to 1 belonged to class one, which indicating slight pollution level (Fig. 3). Compared to 2013, the Igeo values of nine heavy metals of 2014 changed slightly with mean values, which also indicating that the study area was unpolluted by these metals. However, changed occurred between $\mathrm{Pb}$ and $\mathrm{Cu}$, both of them shown unpolluted to moderately contamination degree at LK02 station, and unpolluted at the others. In addition, all sites in the studied area were polluted by $\mathrm{Cd}$ with $50 \%$ of the sites showed unpolluted to moderately contamination degree and $50 \%$ of the sites under moderate polluted. It also can be concluded that $\mathrm{Cd}$ was the most important contamination in the sediments in the studied area, and the contamination threatened by it increased slightly in 2014 .

According to the $E_{r}^{i}$ values of the heavy metals in Table 2 . The $E_{r}^{i}$ values of $\mathrm{Cd}$ in sediments ranged from 51.62 to 84.55 (mean: 67.58) and 50.11 to 136.74 (mean: 92.13) in 2013 and 2014, respectively. The $E_{r}^{i}$ values of Cd indicated a moderate or higher potential ecological risk. Meanwhile, the 
Table 1 Person correlation analysis between heavy metals and characters of the sediments

\begin{tabular}{|c|c|c|c|c|c|c|c|c|c|c|c|c|c|}
\hline & $\mathrm{Pb}$ & $\mathrm{Cu}$ & $\mathrm{Zn}$ & $\mathrm{Cd}$ & $\mathrm{Cr}$ & Co & $\mathrm{Ni}$ & $\mathrm{Hg}$ & As & Clay & Silt & Sand & TOC \\
\hline $\mathrm{Pb}$ & 1 & & & & & & & & & & & & \\
\hline $\mathrm{Cu}$ & 0.45 & 1 & & & & & & & & & & & \\
\hline $\mathrm{Zn}$ & 0.42 & -0.29 & 1 & & & & & & & & & & \\
\hline $\mathrm{Cd}$ & -0.32 & -0.23 & -0.25 & 1 & & & & & & & & & \\
\hline $\mathrm{Cr}$ & 0.31 & -0.42 & 0.12 & 0.28 & 1 & & & & & & & & \\
\hline Co & $0.88 * *$ & 0.33 & 0.52 & -0.43 & 0.25 & 1 & & & & & & & \\
\hline $\mathrm{Ni}$ & 0.56 & -0.38 & 0.44 & -0.17 & 0.62 & 0.54 & 1 & & & & & & \\
\hline $\mathrm{Hg}$ & 0.36 & -0.25 & $0.68^{*}$ & -0.34 & 0.14 & $0.64 *$ & 0.55 & 1 & & & & & \\
\hline As & 0.05 & -0.25 & $0.65^{*}$ & -0.03 & -0.05 & -0.05 & 0.09 & -0.02 & & & & & \\
\hline Clay & 0.46 & 0.01 & 0.54 & $-0.89 * *$ & -0.09 & 0.57 & 0.51 & 0.61 & 0.22 & 1 & & & \\
\hline Silt & 0.52 & -0.47 & $0.79 * *$ & -0.13 & 0.57 & 0.46 & $0.82 * *$ & 0.53 & 0.55 & 0.49 & 1 & & \\
\hline Sand & -0.57 & 0.28 & $-0.78^{* *}$ & 0.57 & -0.29 & -0.59 & $-0.77 * *$ & $-0.65^{*}$ & -0.46 & $-0.85^{* *}$ & $-0.88 * *$ & 1 & \\
\hline TOC & 0.45 & -0.11 & 0.61 & $-0.72 *$ & -0.06 & 0.41 & 0.59 & 0.54 & 0.38 & $0.91 * *$ & $0.65^{*}$ & $-0.89 * *$ & 1 \\
\hline
\end{tabular}

*Correlation is significant at the 0.05 level (two-tailed)

**Correlation is significant at the 0.01 level (two-tailed)

Fig. 3 Geo-accumulation index (Igeo) of values of samples from Longkou Bay. Filled circle represents mean value of Igeo of certain heavy metal; dashed line represents classification of Igeo

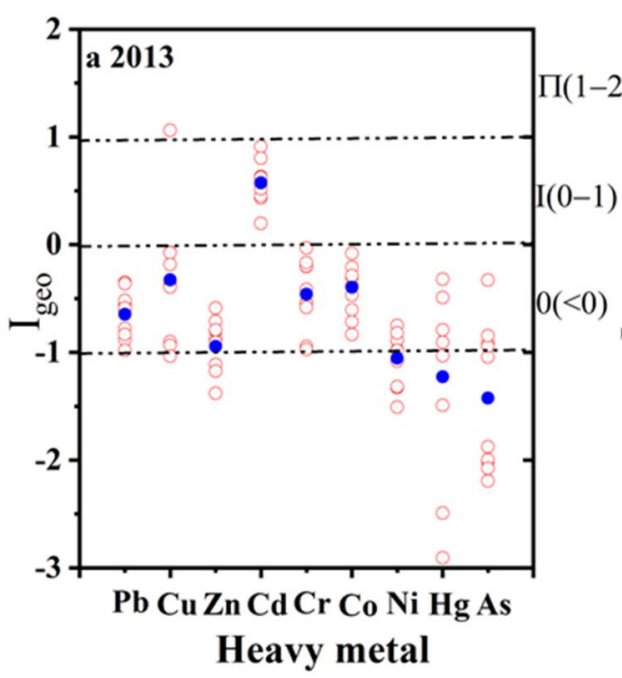

Pb Cu Zn Cd Cr Co Ni Hg As Heavy metal highest $E_{r}^{i}$ values of Cd were observed at LK09 station both in 2013 and 2014, while the $E_{r}^{i}$ value of $\mathrm{Cd}$ in 2014 was 1.6 times that of 2013, indicating that serious potential ecological risk of $\mathrm{Cd}$ existed in this site and nearby in 2014. And the $E_{r}^{i}$ values of $\mathrm{Hg}$ in sediments ranged from 8.00 to 48.00 (mean: 29.07) and 10.67 to 49.33 (mean: 31.15) in 2013 and 2014, respectively, indicating a low potential ecological risk. In contrast, the $E_{r}^{i}$ values for other heavy metals in the sediment were below 10 in both years, indicating a low potential ecological risk.

The $E_{R I}$ values of heavy metals in sediments varied from 99.31 to 138.81 (mean: 126.65 ) and 103.31 to 210.81 (mean: 152.76) in 2013 and 2014, respectively. Results showed that heavy metals posed a low potential ecological threaten in 2013, and a moderate potential ecological threaten in 2014. Meanwhile, we found that the potential eco-risks were mainly caused by $\mathrm{Cd}$ and $\mathrm{Hg}$, which contributed $53.36 \%$ and $22.95 \%$ to $E_{R I}$ in 2013 , and $60.31 \%$ and $20.39 \%$ in 2014 , respectively, indicating that $\mathrm{Cd}$ has the highest potential eco-risk. Hence, $\mathrm{Cd}$ and $\mathrm{Hg}$ were considered the most important potential eco-risks factors in Longkou Bay, which was agreed with the studies of Luo et al. (2010) and Liu et al. (2015). The higher eco-risk of $\mathrm{Cd}$ may be related to the high biological toxicity and the faster accumulation rate in the sediments and aquatic.

Laizhou Bay is an important one part of Bohai. It was worth notice that the ecological risks of $\mathrm{Cd}$ were also highest in the other sea areas of Bohai, such as the Liaodong Bay, the nearshore of Caofeidian and the Yellow River estuary, especially the heavily industrialized Jinzhou Bay, 


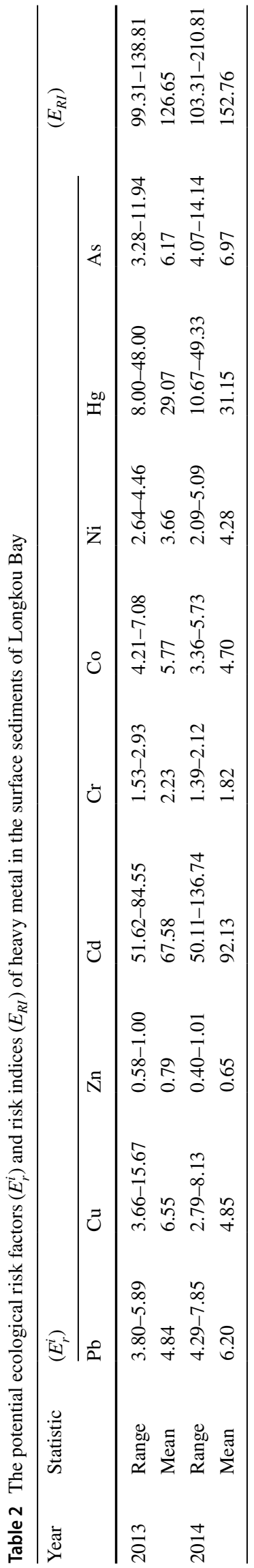

Cd exhibits an extremely high eco-risk (Zhang et al. 2011; Zhu et al. 2018). The above results indicate that it is necessary to strengthen the continuous monitoring and risk assessment of heavy metals, especially $\mathrm{Cd}$, in sediments in Longkou Bay and its adjacent waters under the influence of large-scale offshore artificial island construction.

Acknowledgements This study was financially supported by the National Natural Science Foundation of China (Grants \#4177424, 41371104), and Key Deployment Project of Chinese Academy of Sciences (KZZD-EW-14).

\section{References}

An YN, Wu JZ, Zhu LH, Hu RJ, Yue NN (2010) Response of erosiondeposition pattern to artifical islands construction in Longkou Bay. Mar geol Lett 26:24-30

Armid A, Shinjo R, Zaeni A, Sani A, Ruslan R (2014) The distribution of heavy metals including $\mathrm{Pb}, \mathrm{Cd}$ and $\mathrm{Cr}$ in Kendari Bay surficial sediments. Mar Pollut Bull 84:373-378

Bian SH, Yang YD, Tian ZW, Liu JQ, Hu ZJ (2006) Study on erosional and depositional stability of Lanjiang sand bar in the Longkou Bay. Coast Eng 24:18-24

Ding XG, Ye SY, Yuan HM, Krauss KW (2018) Spatial distribution and ecological risk assessment of heavy metals in coastal surface sediments in the Hebei Province offshore area, Bohai Sea, China. Mar Pollut Bull 131:655-661

Duan CJ, Fang LC, Yang CL, Chen WB, Cui YX, Li SQ (2018) Reveal the response of enzyme activities to heavy metals through in situ zymography. Ecotoxicol Environ Saf 156:106-115

Fang Y, Chen YJ, Tian CG, Lin T, Hu LM, Huang GP, Tang JH, Li J, Zhang G (2015) Flux and budget of bc in the continental shelf seas adjacent to chinese high bc emission source regions. Glob Biogeochem Cycles 29:957-972

Feng XL, Dong WW, Zhuang ZY, Wang YJ, Chen ZH (2009) The calculation of alongshore silt discharge rates and evolution development in the east coast of Laizhou Bay. Period Ocean Univ China 39:304-308

Folk RL, Ward WC (1957) Brazos river bar: a study in the significance of grain size parameters. J Sediment Petrol 31:514-519

Hakanson L (1980) An ecological risk index for aquatic pollution control. A sedimentlogical approach. Water Res 14:975-1001

Han DM, Cheng JP, Hu XF, Jiang ZY, Mo L, Xu H, Ma YN (2017) Spatial distribution, risk assessment and source identification of heavy metals in sediments of the Yangtze River Estuary, China. Mar Pollut Bull 115:141-148

Hill NA, Simpson SL, Johnston EL (2013) Beyond the bed: effects of metal contamination on recruitment to bedded sediments and overlying substrata. Environ Pollut 173:182-191

Liu JH, Song JJ, Cao L, Huang W, Dou SZ (2015) Spatial and temporal distribution, sources and ecological risk assessment of heavy metals in the surface sediments of Laizhou Bay. Asian J Ecotoxicol 10:369-381

Liu XC, Wang YX, Chen J (2017) Study on the water-sediment environment of artificial islands constructed in stages by numerical simulation. Mar Sci Bull 36:302-310

Luo XX, Zhang R, Yang JQ, Liu RH, Tang W, Yan Q (2010) Distribution and pollution assessment of heavy metals in surface sediment in Laizhou Bay. Ecol Environ Sci 19:262-269

Muller G (1969) Index of geoaccumulation in sediments of the Rhine River. Geol J 2:108-118 
Pan SM, Shi XD, Wang JY, Tanner P, Leong SL (2000) Assessing the impact of reclamation activities on recent sedimentation in Victoria Harbour, Hong Kong. Acta Sedimentol Sin 18(1):22-28

Ren P, Sun ZG, Wang CY, Zhao QS, Zhu H (2016) Impacts of construction of artificial islands on the flow-sediment regulation scheme on grain and clay compositions in the Longkou Bay. Adv Mar Sci 34:578-587

Tam NFY, Wong YS (2000) Spatial variation of heavy metals in surface sediments of Hong Kong mangrove swamps. Environ Pollut 110:195-205

Tian HX, Fang LC, Duan CJ, Wang YQ, Wu H (2018) Dominant factor affecting $\mathrm{Pb}$ speciation and the leaching risk among land use types around $\mathrm{Pb}-\mathrm{Zn}$ mine. Geoderma 326:123-132

Usman ARA, Alkredaa RS, Al-Wabel MI (2013) Heavy metal contamination in sediments and mangroves from the coast of Red Sea: Avicennia marina as potential metal bioaccumulator. Ecotoxicol Environ Saf 97:263-270

Wang SL, Xu XR, Sun YX, Liu JL, Li HB (2013) Heavy metal pollution in coastal areas of South China: a review. Mar Pollut Bull $76: 7-15$

Wang L, Coles NA, Wu CF, Wu JP (2014) Spatial variability of heavy metals in the coastal soils under long-term reclamation. Estuar Coast Shelf Sci 151:310-317

Xu XD, Cao ZM, Zhang ZX, Li RH, Hu BQ (2016) Spatial distribution and pollution assessment of heavy metals in the surface sediments of the Bohai and Yellow Seas. Mar Pollut Bull 110:596-602

Yan N, Liu WB, Xie HT, Gao LR, Han Y, Wang MJ, Li HF (2016) Distribution and assessment of heavy metals in the surface sediment of Yellow River, China. Chin J Environ Sci 39:45-51

Zhang YF, Song YG, Wang LJ, Wang NB, Tian J, Ma ZQ, Song L, Wu JH (2011) The ecological risk assessmention of heavy metals in sediments in Jinzhou Bay, Liaoning Province. Fish Sci 30(3):1003-1111

Zhang ZY, Li JY, Zulpiya M, Ye QF (2016) Sources identification and pollution evaluation of heavy metals in the surface sediments of Bortala River, Northwest China. Ecotoxicol Environ Saf 126:94-101

Zhang P, Hu RJ, Zhu LH, Wang P, Yin DX, Zhang LJ (2017) Distributions and contamination assessment of heavy metals in the surface sediments of western Laizhou Bay: implications for the sources and influencing factors. Mar Pollut Bull 119:429-438

Zhao MM, Wang CY, Sun ZG, Sun WL, Lv YC, Zhao HJ, Lu Y (2016) Concentration, distribution and ecological risk assessment of heavy metals in sediments from the tail reaches of the Yellow River estuary. Mar Sci 40:68-75

Zheng YM, Gao MS, Liu S, Zhao JM, Guo F, Wang CM (2015) Distribution patterns and ecological assessment on heavy metals in the surface sediments of Laizhou Bay. Mar Environ Sci 34:354-360

Zhou GZ, Feng XL, Liu J, Liu X, Xu F (2014) Prediction of erosion evolution and deposition in the east coast of the Laizhou Bay after the implemention of the coastal planning. Mar Sci 38:15-19

Zhu H, Bing HJ, Yi HP, Wu YH, Sun ZG (2018) Spatial distribution and contamination assessment of heavy metals in surface sediments of the Caofeidian adjacent sea after the land reclamation, Bohai Bay. J Chem 4:1-8

Zhu H, Bing HJ, Wu YH, Zhou J, Sun HY, Wang JP, Wang XX (2019) The spatial and vertical distribution of heavy metal contamination in sediments of the Three Gorges Reservoir determined by antiseasonal flow regulation. Sci Total Environ 664:79-88

Zhuang W, Gao XL (2014) Assessment of heavy metal impact on sediment quality of the Xiaoqinghe estuary in the coastal Laizhou Bay, Bohai Sea: inconsistency between two commonly used criteria. Mar Pollut Bull 83:352-357

Publisher's Note Springer Nature remains neutral with regard to jurisdictional claims in published maps and institutional affiliations. 